\title{
The role of statistical learning in the acquisition of motion event construal in a second language
}

Article

Accepted Version

Treffers-Daller, J. and Calude, A. (2015) The role of statistical learning in the acquisition of motion event construal in a second language. International Journal of Bilingual Education and Bilingualism, 18 (5). pp. 602-623. ISSN 1367-0050 doi: https://doi.org/10.1080/13670050.2015.1027146 Available at https://centaur.reading.ac.uk/39018/

It is advisable to refer to the publisher's version if you intend to cite from the work. See Guidance on citing.

To link to this article DOI: http://dx.doi.org/10.1080/13670050.2015.1027146

Publisher: Routledge

All outputs in CentAUR are protected by Intellectual Property Rights law, including copyright law. Copyright and IPR is retained by the creators or other copyright holders. Terms and conditions for use of this material are defined in the End User Agreement.

www.reading.ac.uk/centaur 
Central Archive at the University of Reading

Reading's research outputs online 


\section{The role of statistical learning in the acquisition of motion event construal in a second language}

Jeanine Treffers-Daller ${ }^{\mathrm{a} 1}$ and Andreea Calude ${ }^{\mathrm{b}}$

${ }^{\mathrm{a}}$ Institute of Education, University of Reading, UK; ${ }^{\mathrm{b}}$ School of General and Applied Linguistics, University of Waikato, NZ

Learning to talk about motion in a second language is very difficult because it involves restructuring deeply entrenched patterns from the first language (Slobin 1996). In this paper we argue that statistical learning (Saffran et al. 1997) can explain why L2 learners are only partially successful in restructuring their second language grammars. We explore to what extent L2 learners make use of two mechanisms of statistical learning, entrenchment and preemption (Boyd and Goldberg 2011) to acquire target-like expressions of motion and retreat from overgeneralisation in this domain. Paying attention to the frequency of existing patterns in the input can help learners to adjust the frequency with which they use path and manner verbs in French but is insufficient to acquire the boundary crossing constraint (Slobin and Hoiting 1994) and learn what not to say. We also look at the role of language proficiency and exposure to French in explaining the findings.

Keywords: motion event construal, second language acquisition, statistical learning, entrenchment, pre-emption

\footnotetext{
${ }^{1}$ Corresponding author. Email: j.c.treffers-daller@ reading.ac.uk. We are very grateful to two anonymous reviewers for their comments on an earlier version of this paper.
} 


\section{Introduction}

This paper aims to shed further light on frequency effects in second language acquisition, with a particular focus on the domain of motion event cognition, which has been demonstrated to be notoriously difficult for second language learners (Hendriks and Hickmann 2011, Slobin 1996, Treffers-Daller and Tidball in press). The paper builds on Ellis' (2002) seminal paper in which he argues that frequency is a key determinant of language acquisition across a range of domains and on the work of Calude and Pagel (2011) who show that frequency of use is a stable and fundamental feature of human language use. It is clear, of course, that frequency of occurrence of a form is not a sufficient condition for its acquisition. As Gass and Mackey (2002) point out in their reply to Ellis, there are many highly frequent forms (e.g. third person singular - s) which are late acquired, or which remain difficult for learners even at advanced stages. In addition, and more importantly, they note that it would be difficult for learners to figure out which structures are ungrammatical in a language simply on the basis of positive evidence obtained from the input. They argue that learners will need negative evidence to find out, for example, that adverbs cannot be placed after the main verb (*John reads often books). The question is, however, what kind of negative evidence they need. While direct negative evidence (explicit corrections) may not be available, learners may make use of sources of indirect negative evidence (see the next section for a definition) which could provide some of the information they need. One source of such indirect negative evidence could be the frequency distribution of forms in the input.

It is well known that it is possible for adults and children to engage in incidental learning, that is "learning without an intent to learn, or as the learning of one thing, e.g. vocabulary, when the learners' primary objective is to do something else, e.g. to communicate" (Schmidt, as cited in Laufer \& Hulstijn, 2001). Statistical learning is a specific type of incidental learning, first investigated by Saffran, Newport, Aslin, Tunick and Barrueco (1997). They show that adults and children can discover word boundaries by exploiting statistical cues in the input. This line of research has also been developed by Brooks and Tomasello (1999), Goldberg (1995) and Boyd and Goldberg (2011) who investigated how learners make use of statistical information in the input to retreat from overgeneralisations, for example in the argument structure of verbs. Learners need to discover that some verbs (e.g. disappear) can only be used intransitively whilst others can be used intransitively as well as transitively (e.g. bounce). They key learnability problem is how learners avoid using disappear in transitive constructions as in *I disappeared him. 
So far the idea that L2 learners make use of statistical information in the input ${ }^{2}$ has not yet been applied to learning of motion event construal, although the domain of motion event cognition is particularly interesting to investigate the role of frequency on second language acquisition (L2 acquisition). While it is generally accepted that it is difficult for learners to reconceptualise motion in the L2 because of entrenched first language (L1) patterns (Slobin 1996, Carroll and Von Stutterheim 2003), little attention has been paid to the kinds of indirect negative evidence that could be used by learners to avoid target-deviant patterns and opt for targetlike motion event patterns. This paper sets out to explore to what extent frequency of different verbs in the input can provide such indirect evidence and help learners to recover from overgeneralisations that they might make in transferring their L1 patterns to their L2.

As shown in Treffers-Daller and Tidball (in press), English L1 learners of L2 of French have great difficulty with targetlike expression of motion in French. To what extent the frequency distribution of motion verbs in the input can provide cues to learners that can help them to restructure their grammars has not been explored in any detail so far. If frequency is indeed a key determinant of acquisition and learners make analyses of the frequency distribution of items in their input, as Ellis (2002) claims, we can expect L2 learners to notice and be influenced by the frequency distribution of the motion verbs in their input. We assume that with increased exposure to French, learners will start approximating the frequency distribution of motion verbs as displayed by native speakers of French. Because French is a low manner salient language (Antonijević and Berthaud 2012) this could lead, for example, to an increase in learners' use of path verbs, such as arriver "to arrive" and partir "to leave" and a decrease in their use of manner verbs, such as courir "to run" or marcher "to march". Put differently, learners who have had extensive exposure to French can be expected to use motion verbs with frequencies that are more similar to those of native speakers than lower level learners who have had little exposure to French. If it is the case that learners do not only notice the frequency of individual motion verbs but also the patterns in which these occur, statistical learning could indeed provide an important clue to learners regarding the constraints on the use of manner verbs in bounded constructions (see the section on motion event construal in L2 acquisition).

We will also look at the background factors which explain the frequencies with which

\footnotetext{
${ }^{2}$ As one reviewer has pointed out, corpus frequencies are often used as a proxy for information about frequencies in the input to L1 or L2 learners, because studying the actual input to each individual L1 or L2 learner would be extremely complex. Of course it is only an assumption that the frequencies in the corpus correspond to those in the input to the learners.
} 
learners use motion verbs and their success in expressing motion in bounded contexts. Here we expect that it is frequency of exposure to French that has the greatest impact on motion event usage, over and above attitudinal factors or personal characteristics of learners. The frequency data for the current study come from a corpus of stories produced by L1 English adult learners of French of two different levels (21 intermediate and 20 advanced learners who had been on a year abroad) and 23 native speakers of French. These corpus data will be compared with data from large online corpora of French (Sketchengine) and English (the British National corpus) which will provide baseline information about the frequency of motion verbs in both languages.

The paper is structured as follows: first we will briefly summarise the discussion on input and indirect negative evidence in second language acquisition, and then we sketch key issues in second language acquisition of motion event cognition, in particular in relation to the acquisition of French as a second language. In the next section we present our research questions, after which we give details about the research methods. We then present the results, followed by a discussion of the results in the light of the theories presented earlier and we conclude by pointing to issues for further research.

\section{The role of frequency in the input in $\mathrm{L} 2$ acquisition}

The starting point for our literature review is Ellis (2002) seminal paper on the role of frequency in L2 acquisition. In the paper Ellis $(2002,144)$ claims that from a usage-based perspective (Tomasello 2009, Bybee 2003) frequency is a key determinant for language acquisition because

\footnotetext{
"the acquisition of grammar is the piecemeal learning of many thousands of constructions and the frequency-biased abstraction of regularities within them. Language learning is the associative learning of representations that reflect the probabilities of occurrence of form-function mappings."
}

Of course, as pointed out by Gass and Mackey (2002) in their reply to Ellis, frequency cannot be the only determinant of acquisition because many highly frequent forms such as articles (Ionin, Ko, and Wexler 2004, Ionin and Wexler 2003) or prepositions (Jarvis and Odlin 2000) continue to be problematic for learners even at higher levels of proficiency. In addition to the 
positive evidence learners obtain from the input, learners will need negative evidence to enable them to find out which constructions are ungrammatical in the target language. In a study of French learners of English Trahey and White (1993) demonstrated that providing learners with many examples of constructions where adverbs appear in preverbal position (John often reads books) in their English input was not sufficient for these learners to find out that adverbs are not allowable after verbs. For this reason, they argue that learners need negative evidence to recover from transfer-based overgeneralisations which lead learners to assume that adverbs can appear in postverbal position. This then leads to the question what kinds of negative evidence can help learners to restructure their grammars.

Learners can obtain negative evidence in different ways. Direct negative evidence is provided when learners are explicitly told that a particular construction is ungrammatical, but many researchers (Bowerman 1996, Pinker 1989) have shown that this kind of evidence is not frequently available in L1 acquisition. The availability of direct negative evidence in L2 acquisition varies depending on the amount of explicit corrective feedback given to learners. While there is no doubt a role for this in the classroom, in naturalistic L2 acquisition its role is very limited (Mackey 2012). There is, however, a different type of negative evidence, namely indirect negative evidence, which is assumed to be available to learners if certain structures or rules fail to be exemplified in relatively simple constructions where they would be expected (Chomsky 1981). The learner could then exclude such structures or rules from the grammar. In this sense, according to Chomsky (1981), indirect negative feedback may be relevant for language learning, whilst direct negative evidence is not.

According to Doughty and Long (2008) indirect negative feedback is the least studied of the different types of feedback available to second language learners, and they suggest this may be the case because no theoretical arguments rest crucially on it. We do not agree with the latter point because indirect negative evidence could indeed be crucial for learners to recover from overgeneralisation. How learners do this is one of the key problems of second language acquisition, which is why the issue of indirect negative feedback is so crucial for the field.

Several authors have looked into the possibility that frequency distributions can provide at least part of the evidence needed by learners to avoid overgeneralisation. Brooks and Tomasello (1999), for example, argue that hearing a particular form very frequently in a particular construction will lead to this construction being entrenched or strengthened in the learner's mind. As a result, the child will then be less likely to generalise it to novel constructions in which s/he has not heard it before. In addition to entrenchment, statistical 
pre-emption (or blocking) could play a role in constraining overgeneralisations. According to Goldberg (2006) children can notice the fact that particular verbs are used in a marked construction (such as the periphrastic causative construction), as in (1), and not in an unmarked construction (such as the simple transitive construction), such as (2).

(1) The magician made the rabbit disappear

(2) *The magician disappeared the rabbit

In order to make use of indirect negative evidence learners would need to notice, first of all, that (1) is marked; second, that (2) is the alternative unmarked pattern (because many other verbs alternate between transitive and intransitive constructions); and third that, contrary to expectations, (2) does not occur in the input. Having gone through these three steps, learners can draw the conclusion that (2) is not conventional or ungrammatical. Boyd, Ackerman and Kutas (2012) provide some experimental evidence that pre-emption has an independent effect over and above entrenchment. In their study, frequently hearing a novel verb being used intransitively was not sufficient for adults to learn that it cannot be used transitively: crucial evidence was provided by the presence of the parallel marked periphrastic causative in the input. Boyd and Goldberg (2011) also note that the entrenchment hypothesis predicts that verbs which are used with high frequency in one construction should not be available for uses in other constructions, but this prediction is not borne out: creative transitive uses of highly frequent verbs such as swim, snore, pray and cough which are normally used in intransitive constructions, can indeed be found in online corpora. Therefore, it is unlikely that entrenchment on its own can explain the facts, and statistical pre-emption is needed to help learners to retreat from overgeneralisation.

As most of the literature on pre-emption deals with L1 learners, it is not clear at this point to what extent L2 learners can notice to the same extent as L1 learners that some structures which would be expected are in fact absent in the input. If we want to argue that L2 learners will be able to use frequency information in the input in the ways described here, it is of course important to know whether L2 learners are aware of the frequency of target language items. Schmitt and Dunham (1999) demonstrate that this is indeed the case. The "moderately advanced" L2 learners in their study were able to identify the most frequent word among a lexical set of five near synonyms and rate the absolute frequencies of words in ways similar to native speakers. There is also some evidence that they have intuitions about the frequency of multiword items (Backman, as cited in Schmitt \& Dunham, 1999). It is 
unclear how L2 learners develop such intuitions, according to the authors, but they suggest that frequency intuitions could facilitate word learning, or learners might develop these intuitions as a byproduct of learning the words. Either way, the existence of such intuitions clearly shows that L2 learners have access to information about the frequency of words in their L2.

However, as noted above, frequency cannot be the only factor which determines acquisition. Gass and Mackey (2002) point out that more research is needed into the relationship between input saliency and frequency on the one hand and output frequency on the other hand. In a similar vein, De Keyser (2005) suggests that frequency interacts with other factors, such as salience and transparency: it is the interaction between different factors which explains what makes language learning difficult. Transparency also plays a role in L1 acquisition: in their study of the acquisition of posture verbs in Tamil and Dutch, Narasimhan and Gullberg (2011) note that it was not the frequency of linguistic forms in the input but rather the semantic transparency of the form that facilitated verb learning, and they call for further research to investigate the interaction between probabilistic factors such as input frequency and semantic transparency and prelinguistic biases in L1 acquisition.

The current paper sets out to investigate to what extent L2 learners can make use of frequency information in the input to learn particular target language structures used in motion event construals. To the best of our knowledge it has not yet been investigated whether L2 learners can make use of statistical learning (entrenchment and pre-emption) to acquire the domain of motion event construal and retreat from overgeneralisation in this domain. The paper thus aims to make an important contribution to knowledge by making a link between the field of statistical learning and the field of the L2 acquisition of motion event construal. Of course we are aware that frequency information is not the only determining factor: Overall proficiency in the target language, age of onset of L2 learning and frequency of exposure to French are likely to have an impact on students' noticing ability, and these factors will be investigated in the current paper too. In particular among learners who started learning a L2 after the age of twelve this ability may be diminished, as are implicit pattern recognition and memory, which underpin knowledge of what is and is not conventional (Foster 2009). If this is indeed the case, this could explain in part why some learners fail to acquire targetlike expressions in the domain of motion event cognition (see the next section for further details).

\section{Motion event construal in L2 acquisition}


There are important differences between speakers of different languages in the ways in which they describe motion of a Figure across space. These differences are often described in the terminology of Talmy's $(1985,2000)$ typology. According to Talmy, a basic motion event consists of one object (the 'Figure') moving with respect to another object (the referentobject or 'Ground') along a Path (the course followed by the object). In addition, speakers or writers can express the cause or the manner of motion, and these are considered external to the basic event. In Talmy's typology, English and French belong to two different types of languages, Satellite-framed and Verb-framed languages, because of the different ways in which they encode path and manner in motion events. In French, a Verb-framed language (V-language), path is generally encoded in the verb, as in traverser "to cross" in (3a), whereas in English, a Satellite-framed language (S-language), the path component is typically expressed in a particle associated to the verb, such as across, as in (3b).

(3a) Il a traversé la rue en courant (Hickmann and Hendriks 2006, 105)

"He crossed the street running."

(3b) He ran across the street.

In French and other V-languages, manner can be expressed in a subordinate clause, as in en courant "while running" in (3a), but it is often omitted when manner is not foregrounded. In English and other S-languages, on the other hand, manner is generally expressed in the main verb. This way, manner and path are often packed into one clause rather than two, as in ( $3 b)$ where manner is expressed in the main verb ran and path in the particle across.

More recently, Beavers, Levin, and Wei Tham (2010) proposed a revised typology and showed that in many languages both V-framed and S-framed patterns can be found. Thus, it is possible to put path in the main verb in English and manner in a subordinate clause, as in (4) even though this is less common in English. As Pourcel (2004) has shown, the opposite pattern, with manner in the main verb and path in a subordinate clause can be found in French, even though it is rare (see 5).

(4) He crossed the street running

(5) Un homme court en traversant la rue

A man runs crossing the road

\footnotetext{
"A man is running across the road." (Pourcel, 2004: 353)
} 
For L2 learners it is difficult to acquire new ways to conceptualise motion because the conceptualisation patterns they have acquired in their L1 are "exceptionally resistant to restructuring in adult second-language acquisition" (Slobin 2006, 89). L2 learners often continue to rely on the conceptualisation patterns from their L1 and even advanced learners struggle to restructure these in such a way that they conform to L2 patterns (Carroll and Von Stutterheim 2003).

Learners of French whose first language is English need to learn a) that path is generally expressed in the verb rather than in a particle; b) that manner is expressed less frequently in French than in English; and c) that manner can be expressed in the main verb slot if there is no change of location involved, as in (6), but that this is not common if a change of location is predicated (Hickmann, Taranne, and Bonnet 2009), and in particular if this change of location involves a boundary crossing (Aske 1989, Slobin and Hoiting 1994).

(6) Il a couru

"He ran."

For L2 learners of French, it is difficult to learn that (7) can be used to mean that John runs around inside the house (an unbounded event) but not that he runs into the house (a bounded event).

(7) Jean court dans la maison.

"John runs around inside the house." Not: "John runs into the house."

However, some researchers (Cummins 1996, Pourcel 2004, Stringer 2012) dispute the above and claim that other patterns are possible. According to (Stringer 2012) some French manner verbs are path-incorporating (e.g., courir 'run', glisser 'slide', nager 'swim', rouler 'roll', sauter 'jump', tomber 'fall'), and others are non-path-incorporating (e.g. boiter 'limp', chanceler 'wobble', danser 'dance', gigoter 'wriggle', marcher 'walk', ramper 'crawl'). The author claims that only the former, but not the latter may receive a directional interpretation, as in (8).

(8) Gildas a [couru / nagé / glissé / *boité / *dansé / *rampé] à la plage (Stringer 2012, 259) 
Gildas AUX [ran / swam / slid / limped / danced / crawled] P[LOC] the beach.

Gildas [ran / swam / slid / limped / danced / crawled] to the beach.

As the endpoint is not actually reached in the examples given under (8), they may not, in fact, constitute real bounded events: courir à la plage "to run to/towards the beach" does not involve a boundary crossing at all, while courir dans la maison, as in (7), constitutes a clear boundary crossing where the Figure moves into the goal rather than towards the goal (in the directional reading). However, Stringer also provides some evidence from French children and adults that French manner verbs do sometimes appear in bounded constructions (see (Treffers-Daller and Tidball in press) for further discussion). It is also well-known that manner verbs can be used in bounded constructions when they involve a sudden movement as in (9). In such cases the movement is not perceived as an activity but as an instantaneous act (Slobin 2006, 67).

(9) Il se jette dans la maison.

"He throws himself into the room."

The facts presented by Cummins (1996), Pourcel (2004) and Stringer (2012) as well as examples such as (9) make it clear that learning how to express manner in French is highly complex: the constraint on using manner verbs in the main verb slot is not very transparent because the boundary crossing constraint does not apply in the same way to each manner of motion verb (compare se jeter versus courir), and the input to learners is variable because a range of patterns are possible in French and judgements as to the acceptability of manner verbs in bounded constructions vary too. By comparison, acquiring the target-like expression of path seems easier. There is ample evidence that path is expressed in the main verb in French, and acquiring such path verbs is facilitated by the fact that English has some path verbs that are cognate with French (e.g. arrive, depart, enter, etc.). In addition, if learners are sensitive to the frequency of words (Ellis 2002), they will be able to pick up that path verbs are very frequent and manner verbs are less frequent in French on the basis of positive evidence in the input to learners. However, acquiring the target-like expression of manner in boundary crossing events is more difficult because learners would need to receive negative evidence in order to learn what not to say. In other words, there is a learnability issue (White 1991): learners need to discover how to retreat from overgeneralisations which involve the 
non-targetlike use of manner verbs with a directional interpretation in boundary crossing events (e.g. the use of courir dans la maison with the intended meaning "run into the room").

As discussed above, learners cannot recover from overgeneralisation simply by paying attention to the frequency of items in the input. In other words, it is unlikely that the low frequency of manner in the main verb in boundary crossing events is sufficient to acquire the boundary crossing constraint. If, however, learners are sensitive to statistical pre-emption - that is, speakers learn not to use a formulation if an alternative formulation with the same function is consistently witnessed (Boyd and Goldberg 2011) - they might obtain the necessary negative evidence needed for successful acquisition. The construction in (10) could fulfil this function, because manner is expressed in an adjunct, and not in the main verb. The use of manner in the adjunct might pre-empt the use of manner in the main verb in that it might provide evidence to learners that if they want to express manner in this sentence, it needs to be done in an adjunct and cannot be done in the main verb slot.

(10) Jean entre dans la maison en courant

"John enters the house running."

This would of course only work if the alternative construction is sufficiently frequent in the input. Manner adjuncts of this kind are not very frequent in French corpus data: Among the 11,866 occurrences of courir in the French sketchengine corpus, the construction en courant is found 1,007 times (or 7.9 times per million words), and is much less frequent than, for eample, il/elle court, which occurs 1,563 times (or 12.3 times per million words) and the infinitival form courir, which occurs 4,210 times (or 33.2 times per million words). Whether or not en courant is sufficiently frequent in the input to ensure learners can obtain the necessary indirect evidence to retreat from overgeneralisation remains difficult to determine.

\section{Hypotheses of the current study}

The current project aims to contribute to the discussion about restructuring of motion event construal among L2 learners by investigating to what extent statistical learning contributes to learners' success in acquiring the target-like expression of motion. If it is the case that learners are sensitive to frequency with which words are used in the L2 (Schmitt and Dunham 1999), it is possible that L2 learners will become more native-like in their expression of motion construals through a process of adjustment to the frequency patterns in the input. Our 
first hypothesis is therefore that the frequency of motion verbs in the input will be a significant factor in explaining learners' success in acquiring the targetlike expression of motion. In other words, we assume that a key process underlying acquisition in this domain is that of entrenchment: each time a particular verb is used in the input learners note its frequency and the particular construction in which it is used (say a path verb is used as the main verb) and this incrementally strengthens the inference that this is the default position for this verb and other path verbs. L1 English learners of French will start from the assumption that manner is expressed frequently in the L2 (as this is the case in their L1) but these L1based frequency patterns will change under the influence of French input, in that with increased proficiency the patterns will start resembling those of native speakers of French. If this is the case, we expect path verbs will be used more frequently by higher level learners than by lower level learners, and the opposite will be the case for manner of motion verbs. Increasing the frequency of usage of path verbs entails a restructuring of motion in the L2 because expressing path in the main verb is the default in French but not in English.

We will also look into the role of general language proficiency, number of hours spent learning French and other background factors in explaining students' success in acquiring this domain. Our second hypothesis is that it is variables which measure exposure to French that will explain most of the variance in students' success.

We are less confident that making use of statistical learning (entrenchment) will be sufficient for students to produce target-like boundary crossing events involving manner verbs. As explained in the literature review, it is unlikely that learners will be able to obtain the necessary negative evidence to retreat from overgeneralisations (the use of manner in the main verb in boundary crossing events) by paying attention to the frequency of motion verbs in the input only. In addition, learning through pre-emption will be limited because parallel constructions with manner in the adjunct (structures involving gerunds such as en courant) are not very frequent in the input. Our third hypothesis is therefore that many higher level learners will fail to acquire the boundary crossing constraint, even after extensive exposure to the target language.

\section{Methods}

In the current paper we study motion event construal among $41 \mathrm{~L} 1$ English adult learners of French of two different levels (intermediate and advanced) who were studying French at a 
university in the UK at the time of investigation. There were two groups of learners of French, namely 21 first year students who had all obtained an A level in French (mean age 19.3) and 20 final year students (mean age 22.4). Some instruction about motion event construal had been given to the final year students during their second year, but this topic had not been dealt with in great detail. The final year students had all undertaken a one-semester or one-year placement in France the previous year. French native speaker data were obtained from 23 French students (mean age 20.3) who were enrolled on a course at the same university during the time of the current investigation.

Students were asked to record themselves telling two cartoon stories of six pictures each in French. The cartoons were taken from Plauen (1952). Students also filled in a C-test to measure their language proficiency and filled in a questionnaire with background information. Students differed significantly from each other in their overall language proficiency in French as measured with the C-test $(\mathrm{F}(2,61)=105.371, \mathrm{p}<.001)$. A tukey post hoc test showed that all three groups were significantly different from each other, with the native speakers obtaining the highest scores $(92 \%)$, followed by the final year students (77\%), and the first year students obtained the lowest scores (51\%). For further details about the data collection, see (Treffers-Daller and Tidball in press).

The students' story tellings were transcribed in CHAT and analysed with CLAN (MacWhinney 2000). The frequency of use all motion verbs used by learners and native speakers in the above-mentioned controlled production task was compared among the three groups and to the frequency of these verbs input to learners. Information about the latter was obtained from the Sketchengine corpus of French, which consists of 126 million words as used in sources on the internet (see http://www.sketchengine.co.uk/). This was considered to be a more appropriate source of frequencies than Frantext (http://www.frantext.fr/), which consists mainly of literary and philosophical texts. Another possibility would have been to use the Corpus du français parlé (http://sites.univ-provence.fr/delic/corpus/), but this is very small $(440,000)$ and not as easily searchable as Sketchengine.

For the analysis of the picture with the boundary crossing, all learners received a binary grading for this picture alone, either a 1 (if they used the correct expression for the picture) or a 0 (if they did not use the correct expression). For completion, we also scored the native French speakers on their language use ( 1 or 0 , in the same way). Interestingly, some of the native speakers used constructions which are unusual such as courir à l'intérieur d'une banque "run on the inside of the bank" or s'incruster dans la banque "to become embedded in the bank", and these instances were coded as 0 for the purpose of the current study (see the 
literature review for further discussion of variability in French in this domain). Students who did not describe the boundary crossing for this picture were also coded as 0 . All statistics and graphics reported in this paper were produced using the software $\mathrm{R}$ ( $\mathrm{R}$ development Core Team, 2009).

\section{Results}

In this section we describe first of all to what extent the frequency of verbs used by L2 learners matches that of native speakers and how the frequency of verbs in the input to learners impacts on their success in producing target-like motion event construals. Next, we look at explanations for students' success in using motion verbs. In that section we first focus on the impact of proficiency in French and study level and then on the effects of other background factors such as attitudes towards French and amount of exposure to French. After having looked at motion construal in general, we move on to study a specific type of event construal, namely the boundary crossing. We first investigate whether we can predict students' success in describing boundary crossing events on the basis of their success in adjusting the frequency of motion verbs to the frequency of that of native speakers. After that we look at the impact of proficiency in French and study level on students' realisations of the boundary crossing event.

\section{The role of frequency in learning to use motion verbs in L2 French}

We begin this section by pointing out that there are differences in the frequency of use of motion verbs in English and French, see Table 1. It shows that manner verbs such as courir "to run", flotter "to float" and voler "to fly" are more frequent in English than in French, whilst the path verbs arriver "to arrive", entrer "to enter" and partir "to depart" are more frequent in French than in English. This is important, because it is hypothesised that L2 learners start using French verbs first with frequencies that are close to those of the translation equivalents in their L1. In the course of L2 acquisition they will adjust the frequencies of L2 verbs to those of the target language.

Table 1 approximately here 
We first compared the use of motion verbs by native speakers of French against their use by French learners of various proficiency levels. As already discussed, our data contains two groups of French learners: Level 1 group (low proficiency) and Level 3 group (high proficiency). This comparison is summarised in Figure 1. This Figure shows that there are almost no verbs for which all learners match frequencies of use of native speakers well. For some verbs (venir "come", retourner "return"), learners have higher frequencies than native speakers, and conversely, for other verbs, (chercher "search", bousculer "knock over" native speakers have higher frequencies than learners. Notably, there are more verbs in the latter category than the former (as one might expect, native speakers have a wider range of verbs in their repertoires). We do find that there are already some verbs for which Level 3 learners (represented by square symbols) are beginning to approximate the frequencies of use of native speakers (such as entrer "enter/go in", marcher "to march"), showing that they are going in the right direction. Interestingly, marcher is used much less frequently by Level 3 learners than by Level 1 learners, and the opposite is true for arriver "to arrive", which indicates that higher level learners are inclined to reduce the frequency of manner verbs and increase the usage of path verbs.

If learners were to perfectly match the frequencies of use of native speakers of French, then the slope of the regression line between native speakers frequencies and learner frequencies would be exactly 1 (of course, in reality, this would be very difficult to achieve, but an extremely proficient group may come close to matching the native speakers). Figure 1 shows that the slope of the regression line for the Level 3 learners (given in black colour) is closer to 1 then the regression line of the Level 1 learners (given in light grey colour). This suggests that as a group, the Level 3 learners approximate the frequencies of use of motion verbs of the native speakers better than the Level 1 learners. In other words, over time, as learners become more proficient, their frequencies of use match those of the native speakers more closely.

Figure 1 approximately here

Moreover, comparing the use of motion verbs by learners against their use by native speakers, allows us to test whether the differences found between the groups are mediated by frequency of use effects as observed in a corpus of naturalistic French. We obtained frequencies of use (normalised per million words, and logged) from the French corpus hosted by Sketch Engine (Kilgarriff et al. 2004) for each of the motion verbs used by our 
participants. We built a GLM with Poisson Distribution (because we are dealing with nonnormal, count data) for each of our learner groups. The GLM was chosen in order to test whether the corpus frequencies of motion verbs would be a significant predictor in the prodouciton of motion verbs by learner above and beyond the effect expected (and observed) by the native speaker frequencies of these verbs. The results are given in Tables 2 (Level 1 learners) and 3 (Level 3 learners) below. We can see that in both cases, adding the native French corpus frequencies does not have a big effect (the estimate for Sketch in Table 2 is 0.001 and in Table 3, it is 0.0009), but neverthless, the improvement in the model prediction is significant (see the low p-values in both cases, $\mathrm{p}<0.001$ ).

Tables 2 and 3 approximately here

Tables 2 and 3 show that indeed the frequency of use of the motion verbs in naturalistic data plays a significant role in shaping the use of motion verbs for both Level 1 and Level 3 learners. In other words, high-frequency verbs are acquired and used more frequently than low frequency-verbs.

\section{Predicting motion verb usage among L2 learners and native speakers}

In this section we look at the variables which can explain students' motion verb usage. In particular we study the role of language proficiency and study level and the role of other background factors such as attitudes and exposure to French.

The impact of language proficiency and study level on predicting motion verb usage. First of all, we wanted to find out whether or not the C-test scores would be a reliable predictor of the use of motion verbs. We found that there was a correlation between C-test scores and the total number of motion verbs used $(\mathrm{p}<0.001)$, such that higher $\mathrm{C}$-test results correlated with an increase in the use of motion verbs. It is worth mentioning that we used motion verb tokens (not types) here, which we believe makes our finding even more striking. It might be expected that learners and native speakers use a similar number of motion verb tokens because learners could just use the same motion verb over and over again, while native speakers would use a wider range of different motion verbs. Instead, what we find is that even ignoring whether or not the same verb is used or not, learners employ overall fewer motion verbs. At the same time, our learners were also grouped into different study levels, which were similarly correlated with the use of motion verbs $(p<0.001)$, see Figure 2 (left and 
right panels); in other words, the more advanced learners produced a higher number of motion verbs than the beginner learners, but still fewer numbers of motion verbs than native speakers.

Figure 2 approximately here

This led us to ponder whether there was an interaction effect between C-test scores and study level groups. We built a GLM model (as before, using a Poisson distribution) and also controlling for the total word count used, gender of the speaker, and age of the speaker (we did not expect there to be any significant difference across genders and age groups, but we wanted to control for this possible eventuality). We found that the model performed significantly better when an interaction between C-test scores and study level was added then when it was not $\left(\chi^{2}=6.9914, \mathrm{df}=2, \mathrm{p}=0.03\right)$. Table 4 shows details of this model.

Table 4 approximately here

The biggest differences in the interaction were between Level 1 and Level 3 learners $(\mathrm{p}=0.016)$ and between Level 3 learners and native speakers $(\mathrm{p}=0.048)$, such that, the Level 3 learners were producing a much higher number of motion verbs than expected, being closer to the native speakers. This effect is represented in Figure 3, which shows little differentiation in the use of motion verbs between Level 3 learners (black triangles) and native speakers (white circles), despite the fact that there is some differentiation in their respective C-test scores.

Figure 3 approximately here

Motion verb usage and other background factors. Next, we investigated a number of background factors which were self-reported by each of our learners, in order to see if there were any correlations between these and the use of motion verbs. The factors we asked our learners to provide information about were: (1) number of years of French study so far, (2) number of hours of study of French per week, (3) number of years residence in France, (4) use of media (we averaged the various uses reported), self-assessment (we averaged the self- 
assessment grades provided over reading, speaking and writing abilities), and (5) attitudes towards learning (see the Methods section for further details).

We built a Poisson GLM adding these factors to our existing model (which included total word count, gender, age, C-test scores, study level, and the interaction between C-test scores and the study level) to see if any of the background factors might be additional significant predictors of motion verb types used. This was not the case. However, a similar Poisson GLM predicting motion verb tokens use showed that including the background factors significantly improved the model $\left(\chi^{2}=18.662, \mathrm{df}=9, \mathrm{p}=0.028\right)$, and that one of the background factors was a significant predictor, namely the total number of hours spent studying French per week $(\mathrm{p}=0.007)$. Figure 4 shows a plot of this. We discuss implications from these and our previous results in the following section.

Figure 4 approximately here

Predicting success in formulating boundary crossing events

As pointed out in the literature review, describing the boundary crossing constitutes a particular difficulty our English speakers learning French. In the first picture in our narrative elicitation taskthe robber in the story is depicted as entering the bank, which involves a boundary crossing. In English this is typically expressed by a manner verb (run or rush) followed by a directional preposition, generally into, whereas native speakers of French use a path verb, generally entrer "to enter" to describe the event. This poses a problem for native English speakers, because they are tempted to use the construction courir dans la banque "run inside the bank", which is not commonly used with a directional interpretation in French,as they have not yet acquired the constraint on the use of manner verbs in boundary crossings.

In the following section we investigate first of all whether L2 learners who were most successful at adjusting their frequency of usage of motion verbs to the native speaker target were also able to describe the boundary crossing event in target-like ways. After that, we look at the impact of language proficiency and study level on students' realisations of the boundary crossing event. 
The boundary crossing and frequency of motion verbs. We wanted to investigate whether speakers who aligned themselves better with the frequency-of-use of the motion verbs in the Sketch Engine corpus were also more likely to formulate the boundary crossing in a targetlike way. We divided the speakers into two groups: group A consists of those who expressed the boundary crossing in a targetlike way $(n=34)$ and group B of those who did not $(n=30)$, and then averaged for each verb, the number of uses for each group separately. We then matched the two groups against Sketch Engine corpus frequencies, as seen in Figure 5.

Figure 5 approximately here

As can be seen in Figure 5, speakers who were successful in describing the boundary crossing (group A) do not appear to align their motion verb frequencies with the Sketch Engine corpus frequencies any more than those who were unsuccessful (group B). This may come about from the generally low frequency counts of all verbs (this time, we only have one picture and one verb for each speaker). Note, however, also the low frequency counts of certain verbs used by speakers in both groups (for example, speakers from group A use verbs such as conduire "to lead" and retourner "to return" less often than found in the Sketch Engine corpus, and similarly, speakers from group B use verbs such as enjamber "to stride over" and plonger "to plunge" much less frequently than the corpus also). Therefore we conclude that corpus frequencies do not constitute a good predictor for the chance of being successful at describing the boundary crossing in a targetlike way in this case (though we cannot say whether having more boundary crossing pictures in the data and thus increasing the number of verbs would have an effect or not).

The boundary crossing and C-test scores. Our interest here was to see whether either C-test results or study level would be reliable predictors of targetlike use of French boundary crossings.

Figure 6 shows the two models comparing students' success in describing boundary crossings against C-test results and study level. In the left-hand side panel, we compare C-test scores against whether or not the boundary crossing was correctly expressed or not (coded as a binary variable, $1=$ boundary expressed in a targetlike way, $0=$ boundary not expressed in a targetlike way). In the right-hand side panel, we compare Study Level (Level 1 learners, Level 2 learners and native speakers) against boundary crossing production. As expected, 
speakers with higher C-test result scores were more likely to express the boundary crossing correctly (Figure 6, left panel), and native speakers were successful at describing the boundary crossing significantly more often than both groups of learners (Figure 6, right panel). The right panel of the figure also shows that a vast majority of Level 1 learners (18 out of 21), and just under half of Level 3 learners ( 8 out 20) did not express the boundary crossing in a targetlike way. Among these eight Level 3 learners, four used a manner verb with a prepositional phrase (courir dans la banque "run in the bank"), and the other four avoided expressing the boundary crossing altogether and used alternative expressions. The twelve Level 3 learners who were successful in describing this event using the path verb entrer "to enter" employed this verb with the correct subcategorisation frame, namely with the preposition dans "in", which only one Level 1 learner was able to do.

We performed Poisson Logistic Regressions to get check that indeed higher C-test scores are significantly correlated with correct boundary crossing results $(\mathrm{z}=2.838, \mathrm{p}=0.005)$, and that study levels are similarly significantly correlated with boundary crossing results $(\mathrm{z}=3.101, \mathrm{p}=0.002$ for Level 1 learners to native speakers, and $\mathrm{z}=1.720, \mathrm{p}=0.086$ for Level 3 learners to native speakers; the difference between the two learner groups was not significant, $\mathrm{z}=1.208, \mathrm{p}=0.227)^{3}$

Figure 6 approximately here

\section{Discussion and conclusion}

In this paper we looked at the impact of frequency on motion event construals among English L1 learners of L2 French. English and French differ in interesting ways from each other in that English is a satellite-framed language whilst French is a verb-framed language (Talmy 1985, 2000). Although different patterns are possible in both languages, most researchers agree that the default position for path in English is the satellite (e.g. into, out of etc.) whilst in French path and motion are conflated in the main verb slot (entrer "to enter", sortir "to leave", etc.).

As is well-known (Slobin 1996, Von Stutterheim and Nuse 2003, Treffers-Daller and Tidball in press), it is very difficult for learners to learn new ways of expressing motion in a second language. To the best of our knowledge, this is the first paper in which the hypothesis

\footnotetext{
${ }^{3}$ As one reviewer points out, it is possible that the lack of statistical significance is due to the lack of statistical power. If more situations with boundary crossings had been studied, the differences could perhaps have become statistically significant.
} 
is tested that L2 learners make use of statistical learning (Saffran et al. 1997) in restructuring motion event construal in their L2. We hypothesised that L2 learners notice the frequency with which motion verbs are used in their input and adjust the frequency of verbs in their own output to that of native speakers in their environment.

We also looked into the impact of individual differences between students in their success in learning to restructure the patterns in this domain. Our second hypothesis was that variables measuring exposure to French would be more important in predicting students' success than attitudinal variables or variables which measure students' contact with French media.

Finally we hypothesised that restructuring on the basis of statistical learning is only possible for patterns for which the learners have positive evidence in the input. L2 learners of French can obtain such evidence for the fact that path is generally expressed in the main verb in French, and not in a satellite, as in English. For other aspects of motion event construal, in particular the constraints on the use of manner verbs in boundary crossing events, there is no positive evidence in the input to help learners move to the next stage. While learners could, in principle, make use of indirect evidence, namely overt expressions of manner in the adjunct (as in il entre dans la banque en courant "he enters the bank running"), it is not clear whether these constructions are sufficiently frequent in French to pre-empt (Goldberg 1995) usage of manner in the main verb in boundary crossing events. While some learners may be able to make use of the indirect negative evidence provided by sentences in which manner is expressed in the adjunct in French, learners will often be unsuccessful in retreating from the overgeneralisations involving the use of manner in the main verb in boundary crossings, which is common in the L1 but not in the L2

We tested these hypotheses by studying intermediate and higher level adult learners of French in the UK and native speakers of this language and comparing the frequency of usage of motion verbs in story tellings in each group. We found that both learner groups were to a certain extent able to match the frequencies of usage of native speakers, but the higher level learners were better able to do this than lower level learners. This confirms our hypothesis that as learners become more proficient, their frequencies of use of motion verbs match those of native speakers more closely. We also found that the frequency of use of the motion verbs in naturalistic data (as established on the basis of the French Sketchengine corpus) plays a significant role in shaping the use of motion verbs for both Level 1 and Level 3 learners. In other words, high-frequency verbs are acquired and used more frequently than low frequency-verbs by the learners in this study. 
We interpret these findings as strong evidence that L2 learners are indeed sensitive to the frequency of words in the L2 input (Schmitt and Dunham 1999), that frequency of usage is a key determinant of acquisition (Ellis 2002) and that L2 learners engage in statistical learning of motion verbs. Importantly, we also found that learners acquire the subcategorisation frames with the verbs are used (entrer dans "enter in", as opposed to simply entrer "enter"). Thus, as a result of statistical learning, the L2 motion event patterns become entrenched and replace L1-based patterns. Whether or not this means learners have restructured the linguistic surface forms as well as the underlying conceptual structures cannot be determined on the basis of the production data that were used in the current study.

As for other factors which explain students' success in formulating targetlike expressions of motion, it is interesting but not surprising that individual differences in students' overall levels of proficiency and study level explained to a certain degree the frequency with which motion verbs were used. Apart from this, the number of hours spent studying French was found to be a significant predictor of students' usage of motion verbs, whilst attitudinal factors and their usage of French media and other factors were not significant. Interestingly, it is a variable most closely related to degree of exposure to French which explains some of the variance in students' usage of these verbs. This provides additional support to our hypothesis that statistical learning is key to students' success in this domain.

A different picture emerges from the analyses of the scene involving a boundary crossing. It is remarkable that eight out of 20 Level 3 students were unsuccessful at describing this scene despite having had extensive exposure to French during the year abroad. Taken as a group, Level 3 learners were not significantly better at describing a boundary crossing than Level 1 learners. Thus, as predicted in our third hypothesis a large proportion of learners failed to acquire the boundary crossing constraint. We attribute this to the fact that the rules for the use of manner verbs in boundary crossings are far from transparent, which makes it unlikely that learners can acquire these by focusing on positive evidence only. In addition, students' failure is likely to be related to the lack of direct negative evidence and the limited availability of indirect negative evidence in the form of alternative expressions which could pre-empt the use of manner in the main verb in boundary crossings. However, in our study we only looked at one construction involving a boundary crossing, and therefore there may not have been sufficient statistical power to determine whether advanced learners were better at formulating target-like boundary crossings than intermediate learners. Future studies will need to look at a wider range of such scenarios to obtain further evidence in this matter. 
On the basis of the data available in this project it is not possible to establish how learners who were successful in producing targetlike constructions involving boundary crossings (12 out of 20 at Level 3) managed to learn to do this while other learners were unable to do the same. We did investigate whether students' success in describing boundary crossing events could be predicted on the basis of their success in adjusting the frequency of motion verbs to the frequency of usage of these verbs in the Sketchengine corpus but this was not the case. Therefore, we assume entrenchment of patterns in the input (positive evidence) is not sufficient to acquire the boundary crossing constraint. Instead, direct or indirect negative evidence is needed. In this respect learning the boundary crossing constraint is similar to learning argument structure (Boyd, Ackerman, and Kutas 2012, Goldberg 2006, Pinker 1989), in that learning both of these requires learners to retreat from overgeneralisation. Future experimental research in which learners are exposed to different kinds (and different amounts) of indirect negative evidence will be able to shed new light on the extent to which learners can make use of pre-emption to overcome overgeneralisations. 
$\underline{\text { References }}$

Antonijević, Stanislava, and Sarah Berthaud. 2012. "L2 Acquisition of Verbal Constructions: Expressing Motion in L2 French and English." In Constructions in French, edited by Myriam Bouveret and Dominique Legallois, 155-174.

Aske, Jon. 1989. "Path Predicates in English and Spanish: A Closer Look." Berkeley Linguistic Society Papers 14:1-14.

Beavers, John, Beth Levin, and Shiao Wei Tham. 2010. "The Typology of Motion Expressions Revisited." Journal of Linguistics 46 (2):331-377.

Bowerman, Melissa. 1996. "Argument Structure and Learnability: Is a Solution in Sight?" Berkeley Linguistics Society 22:454-68.

Boyd, Jeremy K, Farrell Ackerman, and Marta Kutas. 2012. Adult Learners Use Both Entrenchment and Preemption to Infer Grammatical Constraints. Paper read at 2012 IEEE International Conference on Development and Learning and Epigenetic Robotics (ICDL).

Boyd, Jeremy K, and Adele E Goldberg. 2011. "Learning What Not to Say: The Role of Statistical Preemption and Categorization in A-Adjective Production." Language 87 (1):55-83.

Brooks, Patricia J, and Michael Tomasello. 1999. "How Children Constrain Their Argument Structure Constructions" Language 75 (4): 720-738.

Bybee, Joan. 2003. Phonology and Language Use. Cambridge: Cambridge University Press. Calude, Andreea S, and Mark Pagel. 2011. "How Do We Use Language? Shared Patterns in the Frequency of Word Use Across 17 World Languages." Philosophical Transactions of the Royal Society B: Biological Sciences 366 (1567): 1101-1107.

Carroll, Mary, and Christiane Von Stutterheim. 2003. "Typology and Information Organisation: Perspective Taking and Language-Specific Effects in the Construal of Events." In Typology and Second Language Acquisition, edited by Anna G. Ramat, 365-402. Berlin: De Gruyter.

Chomsky, Noam. 1981. Lectures on Government and Binding. Amsterdam: Foris.

Cummins, Sarah. 1996. "Movement and Direction in French and English." Toronto Working Papers in Linguistics 15:31-54.

DeKeyser, Robert M. 2005. "What Makes Learning Second-Language Grammar Difficult? A Review of Issues." Language Learning 55 (S1):1-25.

Doughty, Catherine J, and Michael H Long. 2008. The Handbook of Second Language Acquisition. Oxford: Blackwell.

Ellis, Nick C. 2002. "Frequency Effects in Language Processing." Studies in Second Language Acquisition 24 (02): 143-188.

Foster, Pauline. 2009. Native-like Selection in Second Language Acquisition: The Effects of Age, Aptitude and Socialisation: Full Research Report. Swindon: ESRC.

Gass, Susan M, and Alison Mackey. 2002. "Frequency Effects and Second Language Acquisition." Studies in Second Language Acquisition 24 (2): 249-260.

Goldberg, Adele E. 1995. Construction Grammar: Wiley Online Library.

Goldberg, Adele E. 2006. Constructions at Work: The Nature of Generalization in Language. Oxford: Oxford University Press.

Hendriks, Henriëtte, and Maya Hickmann. 2011. "Expressing Voluntary Motion in a Second Language: English Learners of French." In Language and Bilingual Cognition edited by Vivian Cook \& Benedetta Bassetti, 315-340. New York and Hove: Psychology Press. 
Hickmann, Maya, and Henriëtte Hendriks. 2006. "Static and Dynamic Location in French and in English." First Language 26 (1): 103-135.

Hickmann, Maya, Pierre Taranne, and Philippe Bonnet. 2009. "Motion in First Language Acquisition: Manner and Path in French and English Child Language." Journal of Child Language 36:705-741.

Ionin, Tania, Heejeong Ko, and Kenneth Wexler. 2004. "Article Semantics in L2 Acquisition: The Role of Specificity." Language Acquisition 12 (1): 3-69.

Ionin, Tania, and Ken Wexler. 2003. "The Certain Uses of the in L2-English." In Proceedings of the 6th Generative Approaches to Second Language Acquisition Conference, edited by Juana M.Liceras et al., 150-160. Somerville, MA: Cascadilla.

Jarvis, Scott, and Terence Odlin. 2000. "Morphological Type, Spatial Reference, and Language Transfer." Studies in Second Language Acquisition 22 (4):535-556.

Kilgarriff, Adam, Pavel Rychly, Pavel Smrz, and David Tugwell. 2004. "The sketch engine." In Proceedings of the 2004 Euralex Conference, 105-115.

Laufer, Batia, and Jan Hulstijn. 2001. "Incidental Vocabulary Acquisition In A Second Language: The Construct of Task-Induced Involvement." Applied linguistics 22 (1): $1-26$.

Mackey, Alison. 2012. Input, Interaction, and Corrective Feedback in L2 Learning: Oxford University Press Oxford, UK.

MacWhinney, Brian. 2000. "The CHILDES Project: Tools for Analyzing Talk: Volume I: Transcription Format and Programs, Volume II: The Database." Computational Linguistics 26 (4): 657-657.

Narasimhan, Bhuvana, and Marianne Gullberg. 2011. "The Role of Input Frequency and Semantic Transparency in the Acquisition of Verb Meaning: Evidence from Placement Verbs in Tamil and Dutch." Journal of Child Language 38 (3): 504-532.

Pinker, Steven. 1989. Learnability and Cognition: The Acquisition of Argument Structure. Cambridge, MA: MIT Press.

Plauen, Erich O. 1952. Vater und Sohn. 2 vols. Ravensburg: Ravensburger Taschenbuch.

Pourcel, Stéphanie. 2004. "Rethinking 'Thinking for Speaking'." In Proceedings of the Annual Meeting of the Berkeley Linguistics Society 29: 349-358.

R: A Language and Environment for Statistical Computing. R Foundation for Statistical Computing,Vienna, Vienna.

Saffran, Jenny R, Elissa L Newport, Richard N Aslin, Rachel A Tunick, and Sandra Barrueco. 1997. "Incidental Language Learning: Listening (and Learning) out of the Corner of Your Ear." Psychological Science 8 (2): 101-105.

Schmitt, Norbert, and Bruce Dunham. 1999. "Exploring Native and Non-Native Intuitions of Word Frequency." Second Language Research 15 (4): 389-411.

Slobin, Dan. 1996. "From "Thought and Language" to "Thinking for Speaking"." In Rethinking Linguistic Relativity, edited by John J. Gumperz and Stephen C. Levinson, 70-96. Cambridge: Cambridge University Press.

Slobin, Dan. 2006. "What Makes Manner of Motion Salient? Explorations in Linguistic Typology, Discourse, and Cognition." In Space in Languages: Linguistic Systems and Cognitive Categories, edited by Henriëtte Hendriks and Maya Hickman, 59-81. Amsterdam/Philadelphia: John Benjamins.

Slobin, Dan, and Nini Hoiting. 1994. "Reference to Movement in Spoken and Signed Languages: Typological Considerations." In Proceedings of the Berkeley Linguistics Society 20: 487-505.

Stringer, David. 2012. "Spatial Feature Assembly in First and Second Language Acquisition." Spatial Cognition and Computation 12 (4): 252-274. 
Talmy, Leonard. 1985. "Lexicalization Patterns: Semantic Structure in Lexical Forms." Language Typology and Syntactic Description 3: 57-149.

Talmy, Leonard. 2000. "Toward a Cognitive Semantics, Vol. II: Typology and Process in Concept Structuring." Language, Speech, and Communication. Cambridge, MA: The MIT Press.

Tomasello, Michael. 2009. "The Usage-Based Theory of Language Acquisition." In The Cambridge Handbook of Child Language, edited by Edith L. Bavin, 69-87. Cambridge: Cambridge University Press.

Trahey, Martha, and Lydia White. 1993. "Positive Evidence and Preemption in the Second Language Classroom." Studies in Second Language Acquisition 15 (2): 181-204.

Treffers-Daller, Jeanine, and Françoise Tidball. in press. "Can L2 Learners Learn New Ways to Conceptualise Events? Evidence from Motion Event Construal among EnglishSpeaking Learners of French." In The Acquisition of French in its Different Constellations, edited by Natascha Müller, Katrin Schmitz, and Pedro GuijarroFuentes. Bristol: Multilingual Matters.

Von Stutterheim, Christiane, and R Nuse. 2003. "Processes of Conceptualization in Language Production: Language-Specific Perspectives and Event Construal." Linguistics 41 (5): 851-882.

White, Lydia. 1991. "Adverb Placement in Second Language Acquisition: Some Effects of Positive and Negative Evidence in the Classroom." Second Language Research 7 (2): 133-161. 